\title{
o papel dos periódicos na publicação de dados de pesquisa
}

\section{The Role of Journals in Publishing Research Data}

Com esse número, abrimos um novo volume da Revista Brasileira de História. Assim como nas viradas de calendário, esses marcos nos enchem de expectativa de boas rupturas, de fechamento de ciclos e renovação de compromissos. Apesar disso, o clima da pandemia de Covid-19, que dominou o ano de 2020, arrasta o seu peso para o novo ano. No caso brasileiro, essa sobra vem ainda adensada pela conjuntura política nacional, marcada pelos ataques e desmonte da ciência por parte de um governo federal que já está registrado nos anais da infâmia universal.

No começo desse novo ciclo da Revista, renovamos nosso compromisso com a produção científica de qualidade, de acesso aberto e socialmente responsável. Nessa direção, talvez poucos temas deveriam chamar tanto a nossa atenção quanto o debate acerca da publicação e do acesso aos dados de pesquisas veiculadas em nossos periódicos. A discussão tem avançado muito nos últimos anos, reforçada pelo compromisso com a chamada "ciência aberta". No caso da grande área de Humanidades, o debate tem sido provocado, principalmente, pelas orientações e esforços da SciELO.

Mas, qual a importância da publicação de dados? O que pode ser definido como dado em uma pesquisa em História? Como se preparar para publicar dados e onde fazê-lo? Qual o papel dos periódicos nesse circuito? O que essa nova realidade pode afetar no cotidiano dos autores e autoras?

A primeira pergunta talvez seja a mais fácil de ser respondida. Em um tempo de crescimento e aceleração vertiginosa da produção científica, muitas vezes online, precisamos zelar com mais vigor pela consistência e pelo armazenamento dos dados que sustentam as nossas conclusões. Na sigla em inglês FAIR, a comunidade científica reuniu o que se esperar de dados científicos 
adequadamente produzidos e armazenados: localizáveis, acessíveis, interoperacionais e reusáveis. ${ }^{1}$ Dessas quatro dimensões, a terceira, talvez, seja menos evidente. A demanda por dados interoperacionais envolve o cuidado do pesquisador em usar protocolos universais no momento de planejar e produzir os seus dados, de modo que eles possam ser comparados e agregados, caso haja acesso livre, a outras bases construídas em outros contextos e grupos.

Já a definição do que pode ser considerado dado armazenável varia muito, a depender do contexto disciplinar e da cultura científica. A definição de quais dados devem ser objetos de uma política de armazenamento passa por um debate nessas comunidades. Uma classificação mais ampla divide os dados em estruturados e não estruturados. Uma planilha produzida a partir de uma série documental pode ser um bom exemplo do primeiro tipo, enquanto entrevistas produzidas para uma pesquisa em história oral são consideradas dados não estruturados. Os benefícios dessa prática, para o avanço do conhecimento e para os pesquisadores, podem ser imensos. A consistência dos dados deveria ser objeto de revisão sistemática já no momento da revisão por pares. Para os autores, significa poderem ter acesso aos dados de outras pesquisas, $o$ que pode levar a trabalhos mais ambiciosos e relevantes e evitar a duplicação de esforços idênticos.

No campo da História, precisamos avançar em um amplo debate sobre uma política geral da área para produção, avaliação, abertura e publicação de dados. Em alguns repositórios, os dados podem ser entendidos e tratados como publicações, recebendo, inclusive, citação. Mas é bom lembrar que, para ter seus dados publicados, o pesquisador precisa conhecer e aplicar protocolos definidos e adotados para o tipo de dado com que ele ou ela estão lidando. Parece haver um razoável consenso de que os periódicos não são os espaços adequados para o repositório de dados. Por outro lado, eles podem e devem ter um papel importante na curadoria e na difusão dos valores FAIR entre seus autores.

Apenas para ficarmos em um exemplo mais familiar: é muito comum, em alguns ramos da pesquisa histórica, a transcrição de documentos manuscritos. Algumas vezes eles são publicados nos apêndices de teses e dissertações, mas raramente acompanham a publicação final da pesquisa. Não é comum, ainda, que um artigo que tenha envolvido a transcrição de alguma fonte venha acompanhado de sua publicação integral. O depósito organizado e revisado dessas transcrições em um repositório, com a autoria e a procedência reconhecidas, não só evitaria que outro pesquisador tivesse que transcrever a mesma fonte, como permitiria o seu aprimoramento coletivo e a sua expansão.

Por fim, os repositórios de dados tendem a ser construídos por institui- 
ções mais robustas do que os próprios periódicos. Ao periódico cabe definir sua política de dados públicos e zelar pela sua boa implementação. O SciELO Data está, em seu site, definido como "[...] um repositório multidisciplinar para depósito, preservação e disseminação de dados de pesquisa de artigos submetidos e aprovados para publicação, ou já publicados em periódicos da Rede SciELO, ou depositados no SciELO Preprints" (SciELO Data). Uma visita e exploração do site pode ser um bom exercício para um entendimento mais amplo da importância deste tipo de iniciativa.

26 de janeiro de 2021

Valdei Araujo Universidade Federal de Ouro Preto (UFOP), Instituto de Ciências Humanas e Sociais, Departamento de História, Mariana, MG, Brasil. rbh@anpuh.org <http://orcid.org/0000-0001-8913-2509>

\section{REFERÊNCIAS}

SCIELO DATA. SciELO Data. Disponível em: https://data.scielo.org/. Acesso em: 26 jan. 2021.

TARRANT, Anna; HUGHES, Kahryn. A reutilização de dados qualitativos é um campo subestimado da inovação e da criação de novos conhecimentos nas ciências sociais. 10 jun. 2020. Disponível em: https://blog.scielo.org/blog/2020/06/10/areutilizacao-de-dados-qualitativos-e-um-campo-subestimado-da-inovacao-e-dacriacao-de-novos-conhecimentos-nas-ciencias-sociais/\#.YBAZf8VKi3I. Acesso em 26. jan. 2021.

\section{NOTA}

${ }^{1} \mathrm{O}$ blog SciElo em Perspectiva tem algumas matérias sobre o tema que são uma boa porta de entrada para o debate, como a matéria "A reutilização de dados qualitativos é um campo subestimado da inovação e da criação de novos conhecimentos nas ciências sociais” (Tarrant; Hughes, 2020). 